\title{
Social circumstances in childhood and cardiovascular disease mortality: prospective observational study of Glasgow University students
}

\author{
G Davey Smith, P McCarron, M Okasha, J McEwen
}

\begin{abstract}
Background
Adverse socioeconomic circumstances in childhood have been related to increased cardiovascular disease (CVD) risk in adulthood in most, but not all, studies. ${ }^{1}$ The findings of such studies can be difficult to interpret given the association of childhood social circumstances with social conditions and behavioural risk factors for CVD in adulthood. Statistical adjustment for these, however, generally indicates an important additional contribution of childhood socioeconomic background. ${ }^{2}$ In this study we investigate the association between childhood circumstances and CVD mortality among male former students of Glasgow University, who will have experienced a relatively homogeneous and privileged adulthood social environment.
\end{abstract}

\section{Methods and Results}

Students attending the University of Glasgow between 1948-68 were invited to participate in a medical examination carried out by the student health department. ${ }^{3}$ Data collected included sociodemographic data, details of health behaviours and measured blood pressure. Participants were traced through the National Health Service Central Register. Full details are reported elsewhere. ${ }^{3}$ The social class of the fathers of the students was coded to the registrar general's classification, with a combined social class III grouping being used as the distinction between III non-manual and III manual was not introduced until near the end of the recruitment period. Deaths up to 31 December 1998 were included in the analyses. Cox proportional hazards models were used to estimate the association between father's social class and CVD, cancer and other (non-CVD, non-cancer) mortality, adjusted for age and quintile of year of birth (to control for any cohort effect). Adjusted models for CVD included: smoking (no, 1-10, $\geqslant 11$ cigarettes per day) and systolic blood pressure $(\mathrm{mm} \mathrm{Hg})$.

A total of 11755 male students participated in the original examinations; the 3576 female students were younger (as female intake

Table 1 Age adjusted relative risks (95\% confidence intervals) of mortality

\begin{tabular}{llllll}
\hline & \multicolumn{2}{l}{ Cause of death $(n)$} & & & \\
\cline { 2 - 6 } Father's social class (n) & All causes (866) & CVD (339) & Cancer (305) & Other (222) & $C^{\star}(339)$ \\
\hline I (1686) & 1.0 & 1.0 & 1.0 & 1.0 & 1.0 \\
II (3008) & $1.13(0.94,1.38)$ & $1.51(1.08,2.11)$ & $1.11(0.81,1.51)$ & $0.81(0.56,1.16)$ & $1.46(1.05,2.05)$ \\
III (3085) & $1.22(1.00,1.47)$ & $1.63(1.17,2.27)$ & $1.07(0.78,1.46)$ & $1.00(0.70,1.42)$ & $1.66(1.19,2.32)$ \\
IV (492) & $1.24(0.90,1.70)$ & $1.85(1.12,3.07)$ & $1.11(0.65,1.91)$ & $0.81(0.42,1.57)$ & $1.91(1.15,3.17)$ \\
V (125) & $1.32(0.78,2.24)$ & $2.36(1.11,4.99)$ & $0.47(0.11,1.91)$ & $1.34(0.53,3.37)$ & $2.31(1.09,4.89)$ \\
p Value for trend & 0.038 & 0.002 & 0.90 & 0.74 & 0.001
\end{tabular}

All analyses adjusted for quintile of year of birth. *Adjusted for systolic blood pressure and smoking.

increased over time) and provided too few deaths for analysis. We have traced 9887 $(84.1 \%)$ of the male students and father's social class was available for 8856 of these $(89.6 \%)$. As age adjusted results were similar for all men with social class data and for the 8396 men with data available on smoking and blood pressure we report only the latter here. There is a strong trend of increasing risk of all cause and CVD mortality with lower paternal social class, with little trend evident for the other cause of death groups (table 1). Adjustment for systolic blood pressure and smoking had little effect on the findings with respect to CVD mortality.

\section{Discussion}

We have demonstrated a strong and specific association between an indicator of childhood social circumstances and CVD mortality among male former Glasgow University students, in agreement with several other studies. ${ }^{1}$ Our study has the advantage of having collected information on father's occupation at entry to further education (when most students would have been living at home), rather than relying on recall in middle age, which has been used in most studies of this issue. Furthermore, confounding by adulthood circumstances is unlikely to be as problematic as in most studies. Less than $5 \%$ of school leavers entered university over the period of this study ${ }^{4}$ and those who did would generally have received educational credentials that placed them in a privileged social position in adult life. The association is specific for CVD mortality; other broad cause of death groups - which would be equally influenced by adulthood social circumstances and health related behaviours-show no association with father's social class.

A range of factors - low birth weight, chronic infections acquired in childhood, and poor nutrition and growth in childhood-which are related to adverse socioeconomic circumstances in early life have been related to BS8 2PR, UK M Okasha

Department of Public Health, University of Glasgow, Glasgow $\mathrm{J}$ McEwen

Correspondence to: Professor Davey Smith (zetkin@bristol.ac.uk) 
account for the strong association observed here. ${ }^{1}$ Blood pressure and smoking in early adulthood are related to subsequent CVD mortality in this cohort, ${ }^{56}$ however they are not strongly related to father's social class and thus do not confound the association reported here.

The existence of a socioeconomic gradient in CVD mortality among predominantly middle class groups - such as civil servants in the Whitehall study ${ }^{1}$ - has been widely cited as evidence that psychological factors, generated by internalisation of position within social hierarchies, must be important, as there is a low prevalence of material deprivation in adulthood among these groups. ${ }^{7}$ This study, however, indicates that childhood social circumstances strongly influence CVD mortality among a homogeneously affluent adulthood group. The socioeconomic gradient in CVD that is seen among middle class adults could be generated by deprivation in childhood, which will have been almost entirely absent among the most privileged social groups (for example, administrative level civil servants) but will have been experienced by a proportion of other middle class groups in less favoured adulthood social locations.

Funding: World Cancer Research Fund; Chest, Heart and Stroke Association Scotland; Stroke Association.

Conflicts of interest: none.

1 Davey Smith G. Socio-economic differentials. In: Kuh D, Ben-Shlomo Y, eds. A life course approach to chronic disease epidemiology. Oxford: Oxford University Press, 1997:24273.

2 Davey Smith G, Hart C, Blane D, et al. Adverse socio-economic conditions in childhood and cause-specific adult mortality: prospective observational study. BMF 1998;316:1631-5.

3 McCarron P, Davey Smith G, Okasha M, et al. Life course exposure and later disease: a follow-up study based on medical examinations carried out in Glasgow University (1948-68). Public Health 1999;113:265-71.

4 Higher education. (Robbins Report; Cmnd 2154). London: HMSO, 1963.

5 McCarron P, Davey Smith G, Okasha M, et al. Blood pressure in young adulthood and mortality from cardiovascular disease. Lancet 2000;355:1430-1.

6 McCarron P, Davey Smith G, Okasha M, et al. Smoking in adolescence and young adulthood and mortality in later life: prospective observational study. $\mathcal{F}$ Epidemiol Community Health (in press).

7 Syme SL. To prevent disease: the need for a new approach. organisation. London: Routledge, 1996. 